\title{
Grundtvig-litteratur 2006-2009: En bibliografi
}

\author{
Af Aage Jørgensen
}

Nedenstående bibliografi over Grundtvig-litteratur 2005-2009 viderefører tilsvarende bibliografier i Grundtvig-Studier 1968, 1971, 1974, 1979, 1984, 1991, 1997, 2001 og 2006 (kumuleret udgave - dækkende årene 1963-1985 offentliggjort 1986).

Stoffet er ordnet efter bibliografiske kriterier frem for efter emnekredse. Tidsrummet gælder ikke absolut, idet enkelte bidrag af ældre dato er medtaget. Arbejdet er afsluttet 8.9.2009.

Med hensyn til avisstoffet (artikler fortegnet nedenfor i afsnit 6, samt anmeldelser fortegnet i forbindelse med de arbejder, de omhandler) gælder, at bibliografien ikke gør krav på fuldstændighed. Medtaget er i alt væsentligt, hvad også bibliotek.dk har fundet det rimeligt at redde fra glemsel.

\section{Bibliographica}

Jørgensen, Aage, "Grundtvig-litteratur 2001-2005. En bibliografi", Grundtvig-Studier 2006, 240-261.

\section{Udgaver}

Grundtvigs Prodikener $i$ Vartov, V-VIII, udg. af Jette Holm og Elisabeth Glenthøj i samarbejde med Christian Thodberg, 2007, 381, 412, 413 og 459 s. (V: Kirkeaaret 1842-43; VI: Kirkeåret 1843-44; VII: Kirkeåret 1844-45; VIII: Christian Thodberg, Indledning og kommentar til Grundtvigs prodikener $i$ Vartov 1842-45 (bind 5, 6 og 7)). (Anm.: Erik Kelstrup, Dansk Kirketidende, 159, 2007, 347-348).

\section{Bøger}

Ahlburg, Kirsten \& Karl Aage Kirkegaard, Grundtvigs liv, 2005, 92 s. (Frilæsningsbog fra Læseværkstedet, Special-pædagogisk Forlag).

Bhattacharya, Asoke, Education for the People. Concepts of Grundtvig, Tagore, Gandhi and Freire. Kolkata, 2008, 240 s. (Indhold bl.a.: J. H. Schjørring, "Foreword", 7-10; *“N. F. S. Grundtvig: Educationist Extraordinary. Homage of an Indian Adult Educator", 52-64; "Grundtvig and the Third World. Democracy, Development and Enlightenment", 65-92; "Glimpses of Grundtvig's Thoughts on Education and Economic Cooperation", 93-108; *"Folk High School and Cooperative Movement in Denmark", 109-162; *"Adult Education in India. Relevance of 
Grundtvig", 163-170). (Artikler, de med * mærkede i optryk). (Anm.: Vagn Wåhlin \& Kim Arne Pedersen, Grundtvig-Studier 2008, 194-199).

Birkelund, Regner, Frihed til folles bedste. En oppositionel stemme fra fortiden, 2008, 685 s. (Skrifter udg. af Grundtvig-Selskabet, XXXVIII). (English Summary, 653-664). (Disputats, forsvaret på Aarhus Universitet 31.10.2008; jf. Regner Birkelunds præsentation, "Friheden og det sunde samfund", Humaniora, 24, 2009, 24-27, samt Jens Holger Schjørrings opposition, Dansk teologisk Tidsskrift, 72, 2009, 57-72). (Anm.: Carsten Bach-Nielsen, Kristeligt Dagblad 31.10.2008; Henrik Gade Jensen, Jyllands-Posten 29.10.2008; Ole Pedersen, Friskolebladet, 2008, nr. 19, 469; Ole Vind, Højskolebladet, 2008, november, 16-17; Hans Jørgen Vodsgaard, Kultur.dk, 2008, nr. 2, 14-15).

Bjørn, Claus, Grundtvig som politiker. Udg. af Thorkild C. Lyby, 2007, 264 s. (Skrifter udg. af Grundtvig-Selskabet, XXXVI). (Anm.: Jes Fabricius Møller, Dansk Kirketidende, 159, 2007, 348-350, og Politiken 13.10.2007; Jakob Holm, Kristeligt Dagblad 10.11.2007; Henrik Gade Jensen, Jyllands-Posten 9.10.2007; Arne Mårup, Prcesteforeningens Blad, 98, 2008, 763-764).

Bojsen-Møller, Jutta, Grundtvig og Marie - en fortæelling fra Rønnebceksholm, 2007, 71 s. (Udg. af Næstved Kommune).

Bradley, S. A. J. (red., overs.), N. F. S. Grundtvig. A Life Recalled. An Anthology of Biographical Source-Texts, 2008, 597 s. (Grundtvig in English, 1.) (Part 1, "Grundtvig's Memoirs", 59-177; Part 2, "Memoirs of Grundtvig", 179-341; Part 3, "Index”, 343-597).

Busbee, Mark Bradshaw, N. F. S. Grundtvig's Interpretation of "Beowulf" as a Living Heroic Poem for the People, Ph.D. dissertation, The University of California, Davis, 2005, 340 s. (Jf. Dissertation Abstracts International, 66, 3638).

Cappelørn, Niels Jørgen, Joakim Garff, Hans Grishauge, Irene Ring \& Henrik Wigh-Poulsen (red.), Alle mine kilder. En samling af foredrag om arven efter Grundtvig og Kierkegaard som kilder til inspiration, 2006, 208 s. (Indhold: Anders Fogh Rasmussen, "Grundtvig og Kierkegaard - nogle af mine vigtige kilder", 9-25; Ralf Pittelkow, "Hin enkelte og folkeligheden", 26-46; Suzanne Brøgger, "Havfruesangens himmelblå løver \& en pæl kød", 47-65; Kjeld Holm, "Grundtvig-stemning og Kierkegaardinspiration", 66-83; Birthe Rønn Hornbech, "Alle mine kilder", 84-109; Christine Antorini, "Grundtvig mod min vilje", 110-123; Johannes Møllehave, "Lidt om Grundtvig, lidt om Kierkegaard, en anelse om Dostojevski", 124-140; Sørine Gotfredsen, "Kierkegaard som indre stopklods", 141-157; Jesper Langballe, "Men jeg stander som et Tegn ... Hvad ville præsten Grundtvig i Folketinget?", 158-176; Marianne Mortensen, "Den enfoldige", 177-192; Bertel Haarder, "Alle mine kilder", 193-208). (Jf. Jørgen Elbek, Information 16.3.2007 [om Anders Fogh Rasmussens bidrag]). (Anm.: Chr. Sivertsen, Dansk Kirketidende, 159, 2007, 41-42).

Golf, Olav, Norgesvennen Grundtvig. "Giv mig, Gud, en Salmetunge”, Oslo, 2001, 197 s. (Også som lydbog, fire kassetter). 
Holm, Anders, To samtidige. Kierkegaards og Grundtvigs kritik af hinanden, 2009, 320 s. (Skrifter udg. af Grundtvig-Selskabet, XXXIX). (Anm.: Jørgen Bo Christensen, Dansk Kirketidende, 161, 2009, 152; Niels Højlund, Weekendavisen 3.4.2009; Johannes Møllehave, Kristeligt Dagblad 31.3.2009; Jes Fabricius Møller, Politiken 31.3.2009). (Lettere omredigeret udgave af ph.d.-afhandling, Aarhus Universitet, 2007, med undertitlen: En historisk-systematisk undersøgelse af Kierkegaards og Grundtvigs kritik af hinanden).

Hornbech, Birthe Rønn, Gud, Grundtvig, Grundlov. Statsmagt og åndsfrihed, 2009, 169 s. (Jf. Bente Clausen, "Frihed for Loke såvel som for Thor", Kristeligt Dagblad 4.9.2009 (interview)). (Anm.: Povl Götke, Kristeligt Dagblad 8.9.2009; Palle Weis, Information/Bøger 10.9.2009).

Jensen, Jørgen I., ... det tredje øjeblik. Mellem Grundtvig og Kierkegaard, 2008, 335 s. (Anm.: Carsten Bach-Nielsen, Kristeligt Dagblad 19.4.2008 [samt interview ved Nils Gunder Hansen]; Johs. H. Christensen, Jyllands-Posten 3.5.2008; Jørgen Bo Christensen, Prasteforeningens Blad, 98, 2008, 961-963; Jørgen Elbek, Litteraturmagasinet Standart, 22:2, 2008, 57-58; Niels Højlund, Weekendavisen 30.4.2008; Lars Sandbeck, Politiken 3.5.2008).

Korsgaard, Ove (red.), O ЧЕЛОВЕКЕ В МИРЕ, Moskva, 2008, 140 s. (Russisk oversættelse ved Lidia Shkorkina af En orm - en gud. Om mennesket $i$ verden, med ny indledning af Ove Korsgaard, samt bidrag af Niels Buur Hansen, Hans Hauge, Bosse Bergstedt, Uffe Jonas og Knud Bjarne Gjesing, 1997; jf. Grundtvig-Studier 2001, 234).

Madsen, Helle Krogh \& Lars Nymark Heilesen, Grundtvig. Bliv klogere på livet med N. F. S. Grundtvig, 2006, 67 s. (Anm.: Lisbeth Lomholt, Dansk Kirketidende, 59, 2007, 38-39).

Mitra, Tandra, Asoke Bhattacharya \& Jayanti Alam (red.), Education and Development. Proceedings of the Grundtvig International Conference held at Jadavpur University in January 1999, Kolkata, 2003, 176 s. (Indhold bl.a.: Knud Eyvin Bugge, "Education and Development. Future, Past and Present in N. F. S. Grundtvig's Educational Thinking", 35-55; Pabitra Sarkar, "India's Literacy Scenario. Achievement and Failure", 56-63; Jens Holger Schjørring, "Grundtvig's Educational Ideas and Their Relevance for India Today", 64-79; Ratneswar Bhattacharya, "A Brief Note on Grundtvig", 80-86; Arthur Macdonald Allchin, "N. F. S. Grundtvig. Education for Life. The Place for Religion and Spirituality", 87-97; Aloke Kumar Sinha, "Education and Development. Problems and Strategies", 98-107; Holger Bernt Hansen, "Adult Learning and Democratization in the Third World. Impact and Relevance of Grundtvig's Educational Ideas", 108-121; Lilian Zoellner, "Grundtvig. Life Enlightenment and Democracy", 122-135; Tandra Mitra \& Asoke Bhattacharya, "Indian Perspective of Adult Education. Relevance of Grundtvig”, 136-154; Maj-Lis Foller, "The 'Third Task'. Prospects of CoOperation between Goteborg and Jadavpur Universities", 155-168; Niels Jorgen Jensen, "People's Enlightenment in a Grassroots Perspective The Svendborg Manifesto", 170-174). 
Rasmussen, Bruno, For han er god - noget om Grundtvigs liv og salmer, 2007, $85 \mathrm{~s}$.

Raahede, Uffe, Grundtvig, Efterskolen \& Medborgerskabet - en introduktion, 2006, $134 \mathrm{~s}$.

Tulinius, Bjørg, m.fl. (red.), Efterdønninger. Grundtvig $225 \stackrel{2}{ }$ å, 2008, $192 \mathrm{s.}$ (=Vartovbogen 2008/09). (Ida Auken, "En køkkenbordsgrundtvigianers bekendelser", 9-18; Anders Bondo Christensen, "Grundtvig forbillede i skolen anno 2008?", 17-28; Anders Holm, "Duelighedens og mulighedens skole. Om Grundtvigs og Kierkegaards syn på dannelse", 29-46; Lone Olsen, "Grundtvig i Thy. " - og den har aldrig levet, som klog på det er blevet, han først ej havde kær"”, 47-62; Jeppe Søe, "Lønnes mulighedsværdi", 63-80; Thurid Pörksen, "På tværs af grænser", 81-94; Kim Arne Pedersen, "Erica Simon og Grundtvig", 95-108; Bente Dahl, "Grundtvig, folkeoplysningen, demokratiet og hvad så nu? Grundtvig og mig", 109-122; Martin Ågerup \& Henrik Gade Jensen, "Kampen om Grundtvig", 123-138; Anders Thyrring Andersen, "Man maa slippe Grundtvig for at faa fat i ham igen'. Martin A. Hansens forhold til Kierkegaard og Grundtvig", 139-158; Thomas Bredsdorff, "Undskyld, kan De vise mig vej til fronten?", 159-166; Hans Hauge, "Frisindet genmæle", 167-182; Niels Boserup, "Arven fra Grundtvig gavner danske arbejdspladser i dag. Selvstændighed på gulvet og viljen til at tage ansvar er ukendt mange steder i verden", 183-186; Bent Lumholt, "Syngemesteren", 187-190).

\section{Dele af boger}

Aller, Edith, Børns bibelhistorier. Sprogbrug, historie og function, 2009, 348 s. (Heri: "Fra Grundtvig til Kalkar. Bibelhistorie og fortælleform i 1800tallets første halvdel", 150-153 og 177-178 [om "En liden Bibelkrønike for Børn og Menigmand"]).

Auken, Sune, "Nordisk mytologi og salmedigtning - N. F. S. Grundtvig" i Klaus P. Mortensen \& May Schack (red.), Dansk litteraturs historie, bd. II: 1800-1870, 2008, 199-237.

Birkelund, Regner, "Grundtvig og demokratiet. Om oplysning, dannelses og demokrati" i Ove Korsgaard (red.), Poetisk demokrati. Om personlig dannelse og samfundsdannelse, 2001, 28-47.

Bjerg, Svend, Tro og erfaring, 2006, 141-154 ("Gudserfaringer i nyere danske salmer").

Bjerre, Karen (red.), Sanghåndbogen, 2006, 556 s. (Undertitel på omslaget: En præsentation af sangene i Højskolesangbogens 18. udgave).

Boll-Johansen, Hans, De danske og de franske. Frankofiliens metamorfoser, 2007, 148-151 ("N. F. S. Grundtvig og Johannes V. Jensen").

Bredsdorff, Thomas \& Lasse Horne Kjældgaard, Tolerance - eller hvordan man laerer at leve med dem, man hader, 2008, 193-208 og 251-252 ("Grundtvig, tolerance og frisind. Om en helt særlig dansk tradition").

Brouwer, Frans [Johannes Cornelis], Vernieuwing in drieklank. Een onderzoek naar de liturgische ontwikkelingen in Denemarken $( \pm 1800$ tot \pm 1950 ). Proefschrift, Rijksuniversiteit te Utrecht, 1990, 600 s. ("Sum- 
mary and Conclusion", 547-555). (Om G passim; spec. "Appendix: N. F. S. Grundtvig”, 510-527).

Busck, Steen, "Romantikken og folkehøjskolen" i Ole Høiris \& Thomas Ledet (red.), Romantikkens verden. Natur, menneske, samfund, kunst og kultur, 2008, 491-501.

Carlsen, Jørgen, "Om Grundtvig og Kold - og begejstringens pædagogik. At undervise er at vise underet" i Hans Skadkær Pedersen \& Niels Reinsholm (red.), Paedagogiske grundfortellinger, (1999), 3. opl., 2005, 70-82.

Chementi, Linda M. \& Birgit Flemming Larsen (red.), Danish Culture, Past and Present: The Last Two Hundred Years. Proceedings of an International Conference Sponsored by The Danish American Heritage Society. Des Moines, Iowa, October 13-16, 2005, Ames, 2006, 393 s., 16 pl. (= The Bridge. Journal of the Danish American Heritage Society, 29:2, 2006). (Indhold bl.a.: Mark C. Mattes, "N. F. S. Grundtvig's Approach to Christian Community and Civic Responsibility", 169-183; Thorvald Hansen, "Grundtvigianism in America, Yesterday and Today", 184-192; Henrik Wigh Poulsen, "Grundtvig's Relevance Today. The Current Debate", 193-202).

Dahler-Larsen, Peter, "Grundtvig og evalueringskulturen - et møde" i Karen Ormstrup Søndergaard (red.), Skolen for livet. Remtrcekket til virkeligheden. Sorømødet 2007, 2007, 34-38. (Heri også: Sune Frølund, "Ånden i naturen", 39-42; om H. C. Ørsted).

Damsholt, Tine, "Kongehånd og folkestemme" i hendes Troen på folkeviljen. Analyse af en tradition $i$ dansk demokratiopfattelse $i$ de sidste 200 àr, 1994, 26-42.

Davidsen, Ole, "Den liturgiske hymne. Et udkast til bestemmelsen af salmen som helligtekst" i Ole Davidsen, m.fl. (red.), Litteraturen og det hellige. Urtekst - Intertekst - Kontekst, 2005, 144-163. (Acta Jutlandica LXXX:1, Teologisk serie 21). (Om "Et Barn er født i Bethlehem").

Elbek, Jørgen, "Grundtvig i bronze" i Knud Munck \& Helge Rørtoft-Madsen (red.), Kampen mod svampen. Facetter af Ebbe Kløvedal Reich, 2006, 203-214.

Fibiger, Johannes, Gerd von Buchwald Lütken \& Niels Mølgaard (red.), Litteraturens tilgange, 2. reviderede/supplerede udg., 2008, 567 s. (1. udg., 2001, 559 s.). (Heri: Johnny Kondrup, "Biografisk metode", 57-75, med læsning af "Strandbakken ved Egeløkke" 69-75; Hans Hauge, "Dekonstruktionisme", 243-274, med læsning af "Strandbakken ved Egeløkke" 266-272; id., "Postkolonialisme", 359-386, med læsning af "Danmarks Trøst" 380-385; de to tekster er aftrykt 451-456).

Gemzøe, Anker, "Tyske piger synger bedre, men ... Den sammenlignende nationalfølelse hos Adam Oehlenschläger med særligt henblik på 'Hiemvee' (1805) og med sideblik på St. St. Blicher og N. F. S. Grundtvig m.fl." i Sven Hakon Rossel (red.), Der Norden im Ausland - das Ausland im Norden. Formung und Transformation von Konzepten und Bildern des Anderen vom Mittelalter bis heute. 25. Tagung der IASS (International Association for Scandinavian Studies) in Wien, 2.7.8.2004, Wien, 2006, 269-280. (Wiener Studien zur Skandinavistik, 15). 
Gleerup, Jørgen, "Demokrati og kultur" i Hans Henningsen (red.), Dansk demokrati, 1994, 60-75. (Om G især 61-63).

Grane, Leif, "Luther i Danmark" i hans Den uberegnelige Luther. Essays om en arv og dens forvaltning, 1992, 133-145, spec. 138 ff. (Kirkehistoriske Studier, 3. rk., 2). (På tysk i Bernd Moeller (red.), Luther und die Neuzeit, Gütersloh, 1983, 135-150).

Gregersen, Niels Henrik, "Nådespagten og menneskets frihed. N. F. S. Grundtvigs tilføjelse til den augustinsk-reformatoriske nådelære" i Bo Kristian Holm \& Else Marie Wiberg Pedersen (red.), Nåden og den frie vilje, 2006, 267-293.

Gregersen, Susanne, "Kirkens dobbelte væsen" i Carsten Bach-Nielsen, m.fl. (red.), Kirken mellem magterne. Artikler tilegnet Jens Holger Schjørring, 2007, 165-176.

Hansen, Villy Meldgaard, "Den danske højskole" i hans Små studier, 2006, 109-119.

Haue, Harry, "Grundtvig og globalisering" i Finn Wiedemann, m.fl. (red.), Mellem kontinuitet og forandring. Festskrift til Jørgen Gleerup, 2007, 83-96.

Hauge, Hans, "Markedets metafysik. Kløvedal og Tolkien" i hans PostDanmark. Politik og astetik hinsides det nationale, 2003, 234-238.

Helleberg, Maria, Danmarkshistorier for børn, ill. af Christian Würgler Hansen, 2. udg., 2005, 255-261 ("Grundtvig"). (1. udg., i to bind, 2002-03).

Henningsen, Hans, Knud Hansen. En legende $i$ dansk åndsliv, 2007, 28-35 ("Grundtvig").

Hessenbruch, Arne, "The Making of a Danish Kantian. Science and the New Civil Society" i Robert M. Brain, Robert S. Cohen \& Ole Knudsen (red.), Hans Christian Orsted and the Romantic Legacy in Science. Ideas, Disciplines, Practices, Dordrecht, 2007, 21-54, spec. 34-37 ("The 1814 Dispute with Grundtvig"). (Boston Studies in the Philosophy of Science, 241). (Se også Frederick Gregory, "Hans Christian Ørsted's Spiritual Interpretation of Natural Science", 399-416, spec. 406-410).

Hougaard, Jens, Romantisk kxrlighed, IV: And og korlighed, 2008, 50-53. (Jf. V: Register, 55).

Høgenhaven, Jesper, “Ægteskab og kærlighed hos Grundtvig” i Katrine Winkel Holm (red.), Og Gud velsignede dem. Fire essays om kirke, karlighed og agteskab, 2005, 81-121.

Højskolesangbogen, 18. udg., 2006. Upag. (Udg. af Folkehøjskolernes Forening i Danmark; med 572 numre).

Høystad, Ole Martin, Hjertets kulturhistorie - fra Gilgamesh til Grundtvig. 2008, 257-265. (På norsk, Oslo, 2003, uden G-kapitlet). (På engelsk, $A$ History of the Heart, London, 2009).

Iversen, Hans Raun, "Grundtvig, menneskelivet og freden" i Kaj Bollmann (red.), Livstegn - en mosaik om fred og kristentro, 1984, 41-46. (Anm.: Hasse Neldeberg Jørgensen, Dansk Kirkeliv, 160, 2008, 278-279).

Iversen, Hans Raun, Grundtvig, folkekirke og mission. Praktisk teologiske vekselvirkninger, 2008. 568 s. (Heri: "Del I. Grundtvig", 15-113, omfattende: "Grundtvigs inkarnatoriske kristendomssyn", 17-34 [< Dansk teologisk Tidsskrift, 1981, 258-277]; "Forholdet mellem det folkelige og 
det kristelige hos Grundtvig som basis for en politisk teologi", 35-53; "Grundtvig som inspiration til mission", 55-77 [< Mission, 94, 1983, 94115]; "Aand er i Mennesket, hvad Pengene er i Verden. Om Grundtvigs Helligåndsteologi”, 79-92 [< Spiritualitet. Festskrift til Anna Marie Aagaard, 1985, 125-138]; "Hvor hører vi Guds ord til os? Livsord, livsudtryk, livstegn, gudsnærvær og kirkesyn hos Grundtvig og i dag", 93-113). (Anm.: Povl Götke, Kristeligt Dagblad 6.6.2008; Ole Buchardt Olesen, Proesteforeningens Blad, 99, 2009, 396-398).

Jacobsen, Anders-Christian L., "Introduktion" i Irenæus, Mod Katterne. Overs. af Ulla Kiel, 1999, 9-85, spec. 72-82 ("Irenæus og Grundtvig").

Jørgensen, Theodor, "Grundtvig and Luther. How Was Grundtvig Influenced by Luther?" i Niels Henrik Gregersen, Bo Holm, Ted Peters \& Peter Widmann (red.), The Gift of Grace. The Future of Lutheran Theology, Minneapolis, 2005, 194-204.

Kondrup, Johnny, "N. F. S. Grundtvig. Fra inspiration til institution" i Jens Anker Jørgensen \& Knud Wentzel (red.), Hovedsporet. Dansk litteraturs historie, 2005, 314-319.

Kongsted, Lisbet \& Sten Østengaard (red.), Dramatik og drømme. Kugler til kanonen. Adam Oehlenschläger, St. St. Blicher, N. F. S. Grundtvig, 2006. 72 s. (Scoop 10; til folkeskolens ældste klasser). - Hertil: Vejledning og kommentarer, 2006, 43 s. Om G, 37-40.

Korsgaard, Ove, "Fra religion til nation som kernen i den kollektive identitet i Danmark" i Jens Holger Schjørring \& Jens Torkild Bak (red.), Udfordringer til folkekirken. Kirken - staten - folket, 2006, 131-168. (Om G, 151-166).

Korsgaard, Ove, "Folket som dannelseskategori. N. F. S. Grundtvig" i Joakim Garff (red.), At komme til sig selv. 15 portratter af danske dannelsestoenkere, 2008, 139-158.

Korsgaard, Ove, "Et læringssted for kulturel mangfoldighed. Grundtvigs forslag til en folkehøjskole i Flensborg" i Erik Lindsø (red.), Granseforeningens årbog, 2009: Mellem adskillige granser. Nationale mindretal i Europa, 2009, 5-11.

Larsen, Ejvind, "Den ufærdige Grundtvig - som alle kender og ingen har læst til ende" i hans Samtaler med tidsånden og opråb imod den. Fra Ejvind Larsens 50 år på Information. Red. af Rune Lykkeberg, 2005, 70-74. (< 15.8.1983).

Lausten, Martin Schwarz, Danmarks kirkehistorie, 3. udg., 2004, 216-29. (1. udg., 1987).

Lundgreen-Nielsen, Flemming, "Nordens pronominale guld. Portræt af et Grundtvig-digt" i Finn Collin \& Jan Riis Flor (red.), Filosofiske Studier, 24: Festskrift tilegnet Docent, dr.phil. Carl Henrik Koch, 2008, 237-250. (Om "Nordens Guld").

Lundgreen-Nielsen, Flemming, "Ragnarok-temaet i dansk litteratur" i Annette Lassen (red.), Det norrøne og det nationale. Studier i brugen af Islands gamle litteratur $i$ nationale sammenhonge $i$ Norge, Sverige, Island, Storbritannien, Tyskland og Danmark, [Reykjavík, 2008], 61-101, spec. 76-82 og 95-96. 
Lundgreen-Nielsen, Flemming, "Concepts of Freedom Reflected in Danish Literature 1754-1802" i Knud Haakonssen \& Henrik Horstbøll (red.), Northern Antiquities and National Identities. Perceptions of Denmark and the North in the Eighteenth Century. Symposium held in Copenhagen August 2005, 2008, 251-276, spec. 271-273; noter, 361-364. (Det Kongelige Danske Videnskabernes Selskab, Historisk-Filosofiske Meddelelser, 101).

Meile, Eva \& Birgit Meister, Salmeordbogen. Salmernes ord og udtryk forklaret $i$ et nutidigt sprog, 2007, 586 s. (Kommentarerne følger Den danske Salmebog's numre). (Interviews med forfatterne: Nils Gunder Hansen, Berlingske Tidende 17.12.2007; Claus Vincents, Kristeligt Dagblad 14.11.2007). (Anm.: Ebba Hjorth, Danske Studier, 2008, 198-204).

Metz, Georg, Danmarks sang. Sangbog med noder, becifringer og sangenes historie, 1994, 68-85. (Kommer hid, I piger små; Langt højere bjerge så vide på jord; Moders navn; Blomstre som en rosengård; Vær velkommen, Herrens år; Det var en sommermorgen; Det er så yndigt at følges ad; Et jævnt og muntert, virksomt liv; Den signede dag).

Metz, Georg, Den danske sang, 2001, 107-139. (Udvidet nyudgivelse af Danmarks sang, 1994).

Metz, Georg, Min danske sang, 2008, 119-162. (Udvidet nyudgivelse af Danmarks sang, 1994, og Den danske sang, 2001).

Møller, Jes Fabricius, Hal Koch. En biografi, 2009, 82-86 ("Grundtvig") og 88-94 ("Forelæsningerne"), jf. reg., 350.

Nabe-Nielsen, Bent, Dannelsens veje. II: Fra oplysningstiden til romantikken, 2008, 255-330 ("Dansk nationalromantik"). (Om G, 268-300; om Chresten Kold, 301-325; resumé, 326-330).

Nielsen, Erik A., "I kor med alle engle. Salmer og englesang hos Luther, Brorson og Grundtvig" i Annegret Friedrichsen \& Charlotte Cappi Grunnet (red.), Engleskrift - om englen i litteraturen, 2006, 32-43.

Pedersen, Inge Lise, "Grundtvigs og grundtvigianismens bidrag til dansk kirkeliv" i Helle Christiansen \& Henning Thomsen (red.), Pastoralteologi, 2007, 59-72.

Pedersen, Kim Arne, "Grundtvig og islam - en skitse" i Carsten BachNielsen, m.fl. (red.), Kirken mellem magterne. Artikler tilegnet Jens Holger Schjørring, 2007, 145-64.

Rasmussen, Anders Fogh, "Frihed og ansvar. Grundtvig og Kierkegaard" i hans 30 taler - 30 år. Udvalgte taler 1976-2006. Red. af Ejvin Bjørnkjær, 2006, 85-109, spec. 99-109. (Tale i Vartov 30.11.2005). (Jf. ndf. under 6. Aviser).

Rasmussen, Jens, Kierkegaards kritik af den triumferende kirke, 2006, $223 \mathrm{s.}$ (University of Southern Denmark Studies in History and Social Sciences, 331). (Om G, spec. 73-84).

Rasmussen, Jens, Religionstolerance og religionsfrihed. Forudscetninger og Grundloven i 1849, 2009, 358 s. (University of Southern Denmark Studies in History and Social Sciences, 381). (Heri afsnittene "N. F. S. Grundtvigs danskhed og forhold til religionsfrihed", 24-30, og "Grundtvigs krav om religiøs frihed og sognebåndsløsning”, 159-167; jf. reg.). 
Rosiek, Jan, "Adam Oehlenschlägers Jesus" i hans Romantiske veksler. Løfter og efterliv, 2008, 75-128, spec. 86-89 og $126 \mathrm{f}$.

Schjørring, Jens Holger, "Grundtvig - poet - præst - politiker" i Ole Høiris \& Thomas Ledet (red.), Romantikkens verden. Natur, menneske, samfund, kunst og kultur, 2008, 341-55.

Svendsen, Erik Norman, Salmer til tiden. Kirkeåret spejlet i 52 salmer, 2003, $114 \mathrm{~s}$. (Ca. en fjerdedel af salmerne er af Grundtvig).

Svendsen, Erik Norman, Syng for livet - guide til salmebogen, 2008, $310 \mathrm{~s}$. (Med salmeregister, men uden salmistregister).

Thyssen, Peter, "Grundtvig og Guds Ord-teologien" i Peter Thyssen \& Anders Moe Rasmussen (red.), Teologi og modernitet, 1997, 66-79. (Tilegnet H. C. Wind på 65-års fødselsdagen 17.5.1997).

Tjørnehøj, Henning, Louis Pio. Folkevaekkeren, 1992, 21-24 ("Den politiske diskrimination af de fattige. Den socialt reaktionære Grundtvig").

Tullberg, Steen, Søren Kierkegaard i Danmark. En receptionshistorie, 2006, 118-122.

Værge, Johannes, “'Omstrål mig'. Forestillinger i salmebogen om det, der er efter døden" i hans Efter døden. En bog om det evige liv, 2008, 211-233, spec. 226-229 (Grundtvig og Kriste-ligheden").

Warming, Per, "Revolution - om en hemmelig hymne" i hans Jorden synger - notater fra forsamlingshuset, 2007, 45-52. (Om "Til Marie, min Trolovede").

Werner, Sven Erik, "Tålt ophold - om den autonome musik, Grundtvig og Kierkegaard i et nutidsperspektiv" i hans Skrålys. Musik - politik musik. Udg. af Niels Krabbe, 2007, 189-204. (Oprindelig i: Grundtvig Kierkegaard. En samtale på høje tid, 2002, 202-222).

Øhrstrøm, Daniel, Vild med dannelse - fra Goethe til Google, 2008, 21-27. (Interview med Harry Haue om "Grundtvig, Madvig og det myndige menneske").

\section{Tidsskriftartikler}

Adamsen, Christian, "Antikvarer og oldforskning på Grundtvigs tid", Grundtvig-Studier 2006, 99-109.

Adriansen, Inge, "Grundtvigs bidrag til udvikling af danske nationale symboler", Grundtvig-Studier 2006, 67-98.

Allchin, A. M., "On 'Grundtvig's eschatology and its realistic significance: A Chinese view' - a prefatory commentary", Grundtvig-Studier 2007, 194197. (Jf. Wen Ge, ndf.).

Auken, Ida, "Jagten på Grundtvig. Hvad kan vi bruge ham til i dag?", Dansk Kirketidende, 158, 2006, 84-87.

Auken, Ida, "Jeg kender et land", Dansk Kirketidende, 161, 2009, 47-49.

Bhattacharya, Asoke, "Tagore, Gandhi and Freire Synthesising their Educational Thoughts with that of Grundtvig. Viewed from a Third World Perspective", Journal of World Education, 2005, nr. 2, 10-25.

Bidstrup, Ulla Morre, "Long Friday eller Good Friday?", Kritisk forum for praktisk teologi, nr. 111, 2008, 59-72. (Forskellige prædikanters måde at 
anskue langfredag på: Tage Schack, Thorkild Grosbøll, Grundtvig, Kjeld Holm, Lars Tjalve).

Bjerg, Svend, "Fra narrativ teologi til erfaringsteologi", Kritisk forum for praktisk teologi, nr. 112, 2008, 2-17. (Bl.a. om G som erfaringsteolog).

Bjerg, Svend, "Grundtvig - for from til folkekirken?", Dansk Kirketidende, 161, 2009, 34-38.

Bock, Mette, "Kærlighed er lysets kilde", Dansk Kirketidende, 160, 2008, 246-247.

Bradley, S. A. J., "Grundtvig, Bede and the testimony of antiquity", Grundtvig-Studier 2006, 110-131.

Bradley, S. A. J., "A signal witness? [Andrew] Hamilton meets Grundtvig (1849-50)", Grundtvig-Studier 2007, 27-43.

Bradley, S. A. J., “'Denne Gaade er godt gjort': Grundtvig's encounter with the riddles of the Exeter Book", Grundtvig-Studier 2008, 19-52.

Brun, Jens, "Grundtvigs kirkelige anskuelse", Dansk Kirketidende, 160, 2008, 104-105.

Bugge, K. E., "En upåagtet dimension i Grundtvigs tanker om 'Anskuelsen”,' Grundtvig-Studier 2006, 53-66.

Bugge, K. E., "Det Chinesiske Examens-Væsen", Grundtvig-Studier 2007, 91-97.

Bugge, K. E., "Nogle grundbegreber i Grundtvigs pædagogiske tanker", Grundtvig-Studier 2008, 118-123 (med bilag ved Bjørn Krab-Johansen, 124-25).

Busbee, Mark Bradshaw, "How Nationalism Enhanced the First Translation of Beowulf", Transverse. A Comparative Studies Journal, 7, 2007, 6481.

Carlsen, Jørgen, "Kors-slutningen. At sige verden ret farvel!", Dansk Kirketidende, 160, 2008, 146-148.

Dansk Kirkesangs årsskrift 2006, 2007, 112 s. (Heri flg. melodistudier: Jørgen Ernst Hansen, "Melodierne til 'Gud Helligånd, vor trøstermand' og 'Påske vi holde", 91-98 [Grundtvig]; Hans Ole Thers, "Melodierne til 'Se, nu stiger solen' og 'Dejlig er den himmel blå’”, 99-101 [Jakob Knudsen, Grundtvig]; Thomas Viggo Pedersen, "Melodierne til 'Nåden, hun er af kongeblod' og 'Fyldt af glæde over livets under"', 102-106 [Grundtvig, Svein Ørnulf Ellingsen]; Arne Berg, "Melodierne til 'Her vil ties, her vil bies"", 107-110 [H. A. Brorson]).

Davidsen, Ole, "Et barn er født", Fyens Stiftsbog, 2007, 17-23.

Drejergaard, Kresten, "Gudstjenesten i salmerne", Fyens Stiftsbog, 2007, 2539, spec. 30-33.

Engberg, Poul, "Dette her grundtvigske. Gudsdatter og Guds søns ægteskab", Vartovbogen 2005/06: Gud og politik, 2005, 191-221.

Eskedal, Anders, "Om N. F. S. Grundtvig og G. P. Brammer", GrundtvigStudier 2008, 7-18.

Ge, Wen, "Grundtvig's eschatology and its realistic significance. Reflections from the Chinese Context", Grundtvig-Studier 2007, 198-216.

Gimmler, Antje, "Værdipolitik eller strukturpolitik. Om sammenhængskraft og moralsk forfald", Social Kritik, nr. 113, 2008, 16-25. 
Hansen, Gregory, "N. F. S. Grundtvig's Idea of Folklore: Resurrecting FolkLife Through the Living Word", The Bridge, 18:2, 1995, 69-84.

Hansen, Nicki B. E., "Salmedigtere overalt i stuen. Lille note om salmens status efter [gymnasie]reformen med særlig hensyntagen til Grundtvig", Dansk Noter, 2007, nr. 4, 23-26.

Hauge, Hans, "Grundtvig: Den evigt opkæftende", Dansk Kirketidende, 161, 2009, 80-86. (Foredrag i Landstingssalen 8.9.2008).

Heggem, Synnøve Sakura, "Nye stemmer omkring Grundtvig", Norsk teologisk tidsskrift, 105, 2004, 178-180.

Heggem, Synnøve Sakura, "Kirke og salmesang", Prismet, 56, 2005, 128137.

Heggem, Synnøve Sakura, "Mennesket i verden - som brud", GrundtvigStudier 2007, 148-167.

Holm, Anders, "The Contemporary Grundtvig. An Addition to Climacus' Critique in "Concluding Unscientific Postscript"' i Niels Jørgen Cappelørn, Hermann Deuser \& K. Brian Söderquist (udg.), Kierkegaard Studies. Yearbook 2005, Berlin/New York, 2005, 24-36.

Holm, Anders, "Når det indre kommer ud. Om Kierkegaards og Grundtvigs kritik af hinanden", Dansk Kirketidende, 160, 2008, 100-103.

Hornbech, Birthe Rønn, "Kirken den er et gammelt hus", Dansk Kirketidende, 160, 2008, 86-87.

Høgenhaven, Jesper, "Grundtvigs videnskabsbegreb. Det skabte menneskeliv. Det særlige og det almene", Tidehverv, 2009, 5-11.

Høgh, Marie, "Højskolesang er åndens bindevæv. Strøtanker over mit højskoleeventyr ... Testrup Højskole foråret 2006", Vartovbogen 2006/07: Højskolesang, 2006, 25-48, især 33-39.

Jonas, Uffe, "Kvinde-Evangeliet: Om Grundtvigs mandebilleder og kvindesyner", Grundtvig-Studier 2007, 168-193.

Jørgensen, Theodor, "En Grundtvig-salme teologisk fortolket", GrundtvigStudier 2007, 98-107. (Om "Velkommen igjen, Guds Engle smaa").

Khader, Naser, "Fødselsdagstale til Grundtvig", Dansk Kirketidende, 158, 2006, 330-332.

Kildegaard, Axel C., "The Impact of N. F. S. Grundtvig on American Immigrants", The Bridge, 19:2, 1996, 79-98.

Kreiner, Cecilia, "Translation Criticism and Unknown Source Texts", Perspectives. Studies in Translatology, 13, 2005, 278-88. (Om Beowulfoversættelser af Grundtvig, Adolf Hansen og Andreas Haarder).

Kvist, Morten, "N. F. S. Grundtvig's Conception of Historical Christianity. An Introduction to the Relationship between Kierkegaard and Grundtvig" i Niels Jørgen Cappelørn, Hermann Deuser \& K. Brian Söderquist (udg.), Kierkegaard Studies. Yearbook 2005, Berlin/New York, 2005, 37-52.

Kvist, Morten, "Genlæsning af Grundtvigs kirkelige anskuelse", Dansk Kirketidende, 159, 2007, 197-198 og 202-204.

Langgaard, Karen, "Jonathan Petersen og Grundtvig", Hymnologi. Nordisk tidsskrift, 35, 2006, 79-102. (JP, 1881-1961, grønlandsk forfatter).

Lundgreen-Nielsen, Flemming, "Grundtvig og censur", Reception, nr. 62, 2007, 31-38. 
Lundgreen-Nielsen, Flemming, "Grundtvig og censuren", Grundtvig-Studier 2007, 44-90. (Med tilføjelse, smst., 2008, 200).

Lundgreen-Nielsen, Flemming, "N. F. S. Grundtvig: Rim-Brev til Nordiske Paarørende, 1832. Tekstkritisk og kommenteret udgave", GrundtvigStudier 2008, 53-117.

Mattes, Mark C., "Reclaiming Grundtvig at Grand View College", GrundtvigStudier 2007, 217-226.

Nielsen, Henning, "Grundtvig og det engang skoleholderløse sogn på Falster", Vartovbogen 2007/08: Menneskesyn i skole- og arbejdsliv, 2007, 135-141.

Nyegaard, Marie Louise, “"Nyaars-Morgen' - historie, fornyelse og fællesskab", Grundtvig-Studier 2007, 258-273.

Nyhus, Ole Jacob, "Ordets gjenklang. Positiv tilknytning for evangeliet med hjelp av Grundtvig", Halvårsskrift for praktisk teologi, 21:2, 2004, 70-81.

Oldrup, Thomas, "Grundtvigianernes Graceland", Højskolebladet, august 2008, 24-25. (Om Marielyst på Ydre Nørrebro).

Osborn, Marijane \& Bent Christensen, “'Skjöld'. A Song by N. F. S. Grundtvig", ANQ. A Quarterly Journal of Short Articles, Notes, and Reviews, 20:3, 2007, 36-43. (Digtet overs. af MO, 37-38, og efterfølgende kommenteret).

Overgaard, Ulrik (medd.), “Til Asylernes Venner og Veninder'. Kommenteret tekstudgivelse om Grundtvigs kamp for asylskolernes frihed", Grundtvig-Studier 2006, 7-14.

Pedersen, Kim Arne, "Grundtvig, Islam og det islamkritiske netværk", Dansk Kirketidende, 158, 2006, 241-246. (Debatindlæg, 281-84, med svar af KAP, 362-368).

Pedersen, Kim Arne (medd.), "To breve fra N. F. S. Grundtvig", GrundtvigStudier 2007, 18-26. (Breve til V. H. Rothe og Jane Blicher).

Rasmussen, Jens \& Anne Riising, "Striden mellem pastor Grundtvig og biskop Mynster om bispesuccessionen. Oversættelse af Mynsters latinske landemodetale i 1840 med kommenteret indledning", Kirkehistoriske Samlinger, 2008, 85-118. (Indledning af JR, 85-104, oversættelse af AR, 104-117).

Rosendal, Bent, "Grundtvig forkynder Israels historie. Om 'Verdens Krønike' 1814", Dansk teologisk Tidsskrift, 69, 2006, 144-156.

Schiøler, Aage, "Det hele menneske og en kristologisk funderet forsynstanke. Om brugen af 'Sjæl' og 'Støv' i to grundtvigsalmer", Grundtvig-Studier 2006, 15-52.

Schiøler, Aage, "En bindestreg, der forsvandt og kom igen", Præesteforeningens Blad, 97, 2007, 122-128. (Om "Venner! Sagde Guds engel blidt").

Schiøler, Aage, "Sangmotivets funktion i to tekstrettelser hos Grundtvig", Grundtvig-Studier 2007, 108-147.

Schiøler, Aage, "Spænding, samspil og frisættelse. En undersøgelse af forholdet mellem inkarnation og eskatologi i Grundtvigs salme 'Midt iblandt os er Guds Rige"”, Grundtvig-Studier 2008, 126-169.

Schiørring, Jens Holger, "Grundtvig og Indien", Det teologiske Fakultet, Aarhus Universitet. Arsskrift, 2007, 16-23. 
Sigurðsson, Ingi, “Áhrif hugmyndafræði Grundtvigs á Íslendinga”, Ritmennt. Ársrit Landsbókasafns İslands, 9, 2004, 59-94.

Stokholm, Anja, "Debatforum: Forkyndelse og formidling - i Grundtvigs prædikener og i dag", Grundtvig-Studier 2006, 236-239.

Stølen, Marianne, "Om Grundtvigs sanges liv i Nordamerika", GrundtvigStudier 2008, 170-193.

Suenson, Thomas, "Begrebet folk i bibelsk-kristen forståelse", Tidehverv, 2008, 89-104, spec. 102-103.

Thodberg, Christian, "Jesu Tro. Om Grundtvigs salme 'Gud Herren saae til jorden ned' (1845)”, Dansk Kirkesangs årsskrift, 2006, 33-56.

Ørtved, Arne, "Mennesket er ingen abekat - menneskesynet bag Grundtvigs pædagogiske tanker", Vartovbogen 2007/08: Menneskesyn i skole- og arbejdsliv, 2007, 16-30.

\section{Avisartikler}

Auken, Svend, "Den grundtvigske arv er truet", Kristeligt Dagblad 21.11. 2008.

Bech-Danielsen, Anne, "Alle elsker Grundtvig, men ...”, Politiken 28.8.2007. Birkelund, Regner, "Frihed til fælles bedste", Kristeligt Dagblad 31.10.2008.

Bock, Mette, "Vor tids Grundtvig", Information 10.9.2007. (Om Søren Krarup).

Brun, Jens, "Grundtvig skal revideres", Kristeligt Dagblad 27.6.2005.

Böss, Michael, "Grundtvigs europæiske Danmark", Weekendavisen 31.10. 2008.

Christensen, Bent, "De kristnes liv i en mangfoldig kultur", Kristeligt Dagblad 11.7.2005.

Cini, Pietro, "Ad Grundtvig til", Weekendavisen 29.4.2005.

Hansen, Jan Bo, "En lukket fest", Weekendavisen 16.9.2005. (Samtale med Jes Fabricius Møller).

Heilesen, Lars Nymark, "Tak N. F. S. - I anledning af en 223 års fødselsdag”, Kristeligt Dagblad 8.9.2006.

Hornbech, Birthe Rønn, "Grundtvig som politiker", Kristeligt Dagblad 1.8. 2008.

Jensen, Anders Rou, "Kampen om Grundtvig", Information 22.3.2008.

Jensen, Henrik Gade, "Venstre må søge tilbage til Grundtvig", Berlingske Tidende 10.5.2005.

Jensen, Kristian, "Den værste og den bedste", Information 11.9.2008.

Kassebeer, Søren, "Man bliver aldrig færdig med Grundtvig", Berlingske Tidende 28.5.2005. (Samtale med Sune Auken).

Kassebeer, Søren, "Ud til højre med Grundtvig", Berlingske Tidende 4.6. 2005. (Samtale med Henning Tjørnehøj).

Kjærhus, Thue Damgaard, "Fogh, Grundtvig og de kulturradikale", Information 17.1.2006.

Knudsen, Marie Østergaard, "Grundtvig var lidt for lys i min fars øjne", Kristeligt Dagblad 15.4.2005. (Samtale med Synnøve Sakura Heggem, hvis disputatsforsvar fandt sted i Oslo 16.4.2005).

Krarup, Søren, "Sammenhængskraft og lykke", Information 9.12.2005. 
Larsen, Birgitte Stoklund, "Mennesket er viklet ind i mange forhold", Kristeligt Dagblad 29.7.2009. (Om "Om Mennesket i Verden").

Lehmann, Christian, "Langt højere bjerge". Interviews med Søren Krarup, Margrethe Vestager, Birthe Rønn Hornbech, Villy Søvndal, Svend Auken og Per Stig Møller, Information 22.7., 23.7., 28.7., 31.7., 4.8. og 6.8. 2008.

Madsen, Kristian Levring, "Ilden for fædrelandet", Kristeligt Dagblad 17.1.2006.

Mikkelsen, Morten, "Grundtvig og Kierkegaard med nye øjne", Kristeligt Dagblad 30.11.2005. (Om Vartov-foredragsrækken "Alle mine kilder").

Møller, Jes Fabricius, "Grundtvig og Grundtvig", Politiken 6.9.2005.

Møller, Jes Fabricius, "Grundtvig, nazisme, krig og demokrati”, Berlingske Tidende 23.8.2005.

Nielsen, Erik A., "I kor med alle engle", Kristeligt Dagblad 20.12.2006. (Om englemotivet hos $\mathrm{G}$ og Ingemann).

Pedersen, Rasmus Brun \& Christian Elmelund-Præstekær, "EU kan lære af Grundtvig”, Berlingske Tidende 30.6.2006.

Rasmussen, Anders Fogh, "Giv Gud en hjælpende hånd", Kristeligt Dagblad 1.12.2005. (Forkortet version af Vartov-foredrag 30.11.2005; jf. også Højskolebladet, 2006, nr. 1, 20-21).

Tjørnehøj, Henning, "Grundtvig negligerede den sociale frihed", Kristeligt Dagblad 5.9.2008. (Replik til Birthe Rønn Hornbech, "Grundtvig som politiker", smst. 1.8.2008; debatindlæg af Ole Petersen, "Grundtvig havde sans for den sociale frihed", smst. 9.9.2008).

Tjørnehøj, Henning, "CEPOS-manden Grundtvig”, Berlingske Tidende 30.10. 2008.

Tjørnehøj, Henning, "Grundtvig læst af Ebbe Kløvedal Reich”, Kristeligt Dagblad 30.12.2008.

Vincents, Claus, m.fl., "Vi kommer ikke uden om Grundtvig", Kristeligt Dagblad 7.9.2006.

Vind, Ole, "Grnndtvig og sammenhængskraften", Information 6.9.2008.

\section{Varia}

Auken, Sune, Sagas spejl, 2005. (Jf. "Disputatsforsvar", Nordica, 23, 2006, 211-255 [Johnny Kondrup, "Anden officielle opposition ved Sune Aukens disputatsforsvar den 3. juni 2005", 211-230; Svend Skriver, "Har formen intet at betyde? Opposition ex auditorio til Sune Aukens disputats", 231-236; Sune Auken, "Svar til Johnny Kondrup og Svend Skriver", 237-255]). (Anm.: Johannes Adamsen, Religionsvidenskabeligt Tidsskrift, nr. 47, 2005, 97-100; Jakob Bækgaard, Vandfanget, 10. årg., 2005, nr. 4, 90-93; Johs. H. Christensen, Jyllands-Posten 3.6.2005; Heidi Friborg Christophersen, Folkeskolen, 2005, nr. 28-32, 38 og 40; Poul Engberg, Højskolebladet, 2006, nr. 9, 18, og Dansk Kirketidende, 158, 2006, 251-253; Niels Højlund, Weekendavisen 3.6.2005; Olav Klonteig, Folkehøgskolen, 2006, nr. 3, 20-21; Laust Riis-Søndergaard, Højskolebladet, 2005, nr. 11, 12-13; Lars Sandbeck, Politiken 1.6.2005; Finn Stefánsson, Religion, 2005, nr. 4, 61-62; Lars Tjalve, Kristeligt Dagblad 
3.6.2005; Dag Thorkildsen, Norsk teologisk tidsskrıft, 107, 2006, 141142).

16 kernesalmer af N. F. S. Grundtvig. Udvalgt og kommenteret af fem fra Grundtvigsk Forum. 2009. 53 s. (Kommentatorer: Kirsten M. Andersen, Marianne Christiansen, Jørgen Demant, Henrik Wigh-Poulsen og Arne Ørtved). (Anm.: Nana Hauge, Dansk Kirketidende, 161, 2009, 76-78). (Download fra: www.grundtvig.dk/pdf/Samledefortolkninger.pdf).

Bhattacharya, Asoke, "Third Grundtvig International Conference on Education, Communication and Development, India 2007", GrundtvigStudier 2007, 227-235.

Brun, Jens, “'Hvorfor slukker I ikke bare?' Grundtvigianismen i dag”, Fyens Stiftsbog, 2005, 73-82.

Bugge, K. E., "Sigurd Aa. Aarnes in memoriam", Grundtvig-Studier 2007, 913.

Demokratikanon. Udg. af Udvalget til udarbejdelse af en demokratikanon. 2008, 44-45.

Eichberg, Henning, "The physical culture academy: People's education through sport in Denmark", Grundtvig-Studier 2006, 188-209.

Elm, Ebbe, Narvaersmotiver $i$ Grundtvigs Sang-Vark. Grundtvigs salmer loest som poetisk teologi. Om sammenhoengen mellem billedsprog og liturgi som forudsatning for forståelsen af: "Ordet der skaber, hvad det novner", speciale, Aarhus Universitet, 2002, 96 s.

Gaunt, Alan, Delight that Never Dies. Hymn Texts 1997-2003, London, 2003. viii, 190 s. (Heri: "Translations from the Danish of N. F. S. Grundtvig (1783-1872)", 145-171 [22 salmer]).

Gjesing, Knud Bjarne, Finn Frederik Krarup \& Povl Schmidt (red.), Danske littercere tekster 1800-1850, 2002, 58-74. (18 tekster).

Grundtvig-Studier 2005, red. af Jens Holger Schjørring, S. A. J. Bradley, Fl. Lundgreen-Nielsen og Kim Arne Pedersen, 2005. 241 s. (Heri: Peter Balslev-Clausen, "Grundtvig-Selskabet af 8. september 1947. Årsberetning 2004", 225-230; "English Summaries / Danske Resuméer", 231239). (Anm.: Finn Riber Jensen, Dansk Kirketidende, 158, 2006, 130133).

Grundtvig-Studier 2006, red. af Jens Holger Schjørring, S. A. J. Bradley, Fl. Lundgreen-Nielsen og Kim Arne Pedersen, 2006, 285 s. (Heri: Peter Balslev-Clausen, "Grundtvig-Selskabet af 8. september 1947. Årsberetning 2005", 267-272; "English Summaries / Danske Resuméer", 273283). (Anm.: Jens Brun, Dansk Kirketidende, 159, 2007, 195-196).

Grundtvig-Studier 2007, red. af Jens Holger Schjørring, S. A. J. Bradley, Fl. Lundgreen-Nielsen og Kim Arne Pedersen, 2007, 291 s. (Heri: Peter Balslev-Clausen, "Grundtvig-Selskabet af 8. september 1947. Årsberetning 2006", 274-277; Synnøve Sakura Heggem, "Den norske avdeling av Grundtvig-Selskabet af 8. september 1947: Årsberetning 2006-2007", 278; "English Summaries / Danske Resuméer", 279-291).

Grundtvig Studier 2008, red. af Kim Arne Pedersen, S. A. J. Bradley, Flemming Lundgreen-Nielsen og Ulrik Overgaard, 2008, 208 s. (Heri: Peter Balslev-Clausen, "Grundtvig-Selskabet af 8. september 1947. Årsberetning 2007", 201-204; "English Summaries / Danske Resuméer", 
205-208). (Ole Buchardt Olesen, Prasteforeningens Blad, 99, 2009, 429431).

Hansen, Niels Buur, "Medborgerskab - et farvel til den Grundtvig-Koldske pædagogik?" i Alexander von Oettingen, m.fl. (red.), Medborgerskab en udfordring til efterskolen, 2008, 107-115.

Havsteen-Mikkelsen, Mette E., "Vartov-Arkivet - en karakteristik", Fyens Stiftsbog, 2007, 125-131.

Jackson, Jack \& Jody Pennington, "Grundtvig trives i Harlem", Samvirke, 2005, nr. 10, 106-110. (Samtale med Norman Eddy).

Korsgaard, Ove, "Debatforum: Hvordan erindres folkehøjskolens historie?", Grundtvig-Studier 2007, 236-246. (Erstatter fejlbefængt version af debatindlægget i Grundtvig-Studier 2006, 210-220).

Larsen, Christian, Registre til Kirkehistoriske Samlinger 1849-2006, 2007, 244-245.

Larsen, Esben Lunde, Frihedsteenkning hos N. F. S. Grundtvig, speciale, Københavns Universitet, 2008, $78 \mathrm{~s}$.

Larsen, Kurt E., Fra Christensen til Krarup. Dansk kirkeliv i det 20. århundrede, 2007, 171-188 (kapitlet "Grundtvigianismen").

De Levendes Land - poetisk leg med Grundtvig, 2009, 46 s. (Anm.: Nana Hauge, Dansk Kirketidende, 161, 2009, 78-80). (Download fra: www.grundtvig.dk/grundtvigskforum_delevendesland.asp). (Undervisningsmateriale for 7.-9. klasse).

Overgaard, Ulrik, Dengang og $n и$. Den grundtvig-koldske grundskolepadagogik - historisk, systematisk og empirisk belyst, ph.d.-afhandling, Aarhus Universitet, 2008, $369 \mathrm{~s}$.

Pedersen, Kim Arne, "Debatforum: Dannelsesbegrebet som element i folkehøjskolens selvforståelse", Grundtvig-Studier 2006, 221-235.

Riis-Søndergaard, Laust, "Forsker tager temperaturen på de frie skoler", $H ø j-$ skolebladet, 2008, nr. 4, 10-12. (Om Ulrik Overgaards århusianske ph.d.projekt "Den grundtvig-koldske grundskolepædagogik").

Riis-Søndergaard, Laust, "Grundtvigs udsending i Afrika", Højskolebladet, 2004, nr. 21, 16-17. (Samtale med Kachi E. Ozumba).

Sanders, Hanne \& Ole Vind (red.), Grundtvig - nyckeln till det danska?, 2003. (Anm.: Harry Aronson, Grundtvig-Studier 2006, 262-266).

Thorkildsen, Dag, "Mellom Hauge og Grundtvig. Berge Furre som teolog", Kirke og kultur, 2008, nr. 1, 55-65.

Vind, Ole, "En historie om Grundtvigs højskole" i Ole Vind (red.), Grundtvigs Højskole Frederiksborg, 2006, 11-47, spec. 11-17. (Jubilæumsskrift, 1856-2006).

Vinnes, Sølvi Irene, "Vi løbe dig med sang imod". En sammenlignende analyse av noen sentrale julesalmer hos Brorson og Grundtvig, Universitetet i Oslo, 2003, 110 s. (Hovedopgave i kristendomskundskab; bl.a. om salmernes inkarnationsforståelse; utrykt).

Vogel, Norbert, "Paul Röhrig in memoriam", Grundtvig-Studier 2007, 15-17. Walstad, Pål Henning Bødtker, "Dannelse og Duelighed for Livet". Dannelse og yrkesutdanning $i$ den grundtvigske tradisjon, doktoravhandling, Norges teknisk-naturvitenskapelige Universitet, Trondheim, 2006, 353 s. 
Walstad, Pål Henning Bødtker, "Debatforum: Ernst Triers Grundtvigresepsjon. Om dannelse og yrkesdanning i Vallekilde", GrundtvigStudier 2007, 247-257.

Wigh-Poulsen, Henrik, "Venlig vekselvirkning eller forsvar for fundamenterne? Grundtvigske bevægelser i det 20. og 21. århundrede" i Jens Holger Schjørring \& Jens Torkild Bak (red.), Udfordringer til folkekirken. Kirken - staten - folket, 2006, 223-244. (Bl.a. om Jakob Knudsen).

Wåhlin, Vagn, "Popular, religious and social movements. Recent research approaches and qualitative interpretations of a complex of historical problems", Grundtvig-Studier 2006, 132-187.

\section{Websites (jf. Grundtvig-Studier 2006, 261)}

\section{Wikipedia:}

http://da.wikipedia.org/wiki/N.F.S._Grundtvig

Litteratursiden.dk:

www.litteratursiden.dk/sw45341.asp

Google Books. Nordens Mythologi, 2. udg., 1832:

$\mathrm{http}: / /$ books.google.dk/books?id=Toyrlkm69XkC\&printsec $=$ title $\neg$ page $\& \mathrm{~d}$ $\mathrm{q}=\mathrm{n} .+\mathrm{f} .+\mathrm{s} .+$ grundtvig

Internet Archive:

www.archive.org/search.php?query=grundtvig

Internet Archive. Danskeren. Et Tidsskrift, 1850:

www.archive.org/details/danskerenetugeb04grungoog

\section{Andre medier}

Den signede dag, Kirkelig Kulturverksted, Oslo, EXCD 229, 2000. (Iver Kleive, Povl Dissing, Knut Reiersrud).

\section{Korrekturtilføjelse}

Jeg ligger inde med en ATLA/Religion-udskrift over anmeldelser af Grundtvig-udgivelser, som hermed viderebefordres: David Carter, One in Christ, 35, 1999, 292-293; Andrew Louth, Sourozh, 77, 1999, 50-52; Mark C. Mattes, Lutheran Quarterly, 13, 1999, 232-234; David R. Law, Journal of Theological Review, 50, 1999, 398-403; William B. Green, Anglican Theological Review, 81, 1999, 160-161; Jakob Olsen, Journal of Ecclesiastical History, 49, 1998, 580-581; Kenneth Stevenson, Theology, 101, 1998, 306-307; George Pattison, Modern Believing, 39, 1998, 53-55; Cyril S. Rodd, Expository Times, 109, 1998, 288. 